\title{
Determination of Load for Quasi-static Calculations of Railway Track Stress-strain State
}

\author{
D. Kurhan
}

\author{
The Dnepropetrovsk National University of Railway Transport named after \\ academician V. Lazaryan, Department of Railway and Railway's Facilities \\ Lazaryan st. 2, 49010, Dnepropetrovsk, Ukraine
}

Phone: +38 0563731542

e-mail: kurgan@brailsys.com

\begin{abstract}
When calculating the railway track stress-strain state one usually assumes that total strains are brought immediately from applied load and the process dynamics is taken into account by the respective levels of design force. The dynamic component of the design force depends on various factors that are not always taken into account to the full. The analytical analysis of the calculation methods and the experiment testing data resulted in the following recommendations: for freight trains, especially in the conditions of soft rail support, it is advisable to take into account the effect of adjacent wheels; for modern passenger cars there is no significant load dependence on speed, and the main factor of dynamic component is the track fluctuations.
\end{abstract}

Keywords: railway, permanent way, dynamic load, track stress-strain state

\section{Introduction}

Depending on the problem to be solved, one can use both relatively simple twodimensional design models and developed models, which are described with the systems including dozens of equations. Despite the fact that this refers to the interaction of track and rolling stock, still the problems focused on the rolling stock study, and those focused on the railway track study have fundamental differences. Rolling stock models are, in most cases, the systems of motion (vibrations) of the interconnected solids. Typically, such models are mathematically described by Lagrange equations. Railway track operation is more naturally described not as motion of solids, but the strains thereof. Therefore, the railway track is more often mathematically described by the models based directly on theory of elasticity or its numerical representations in the form of finite element method and others. The combination of different approaches in one model greatly complicates their creation and subsequent application so is impractical for most tasks.

Thus, the railway track models in most cases come to a system of bodies (or layers) with elastic strain under load. These models, as a rule, are quasi-static: one of the main 
conditions at their creation is that the strain caused by the applied load are brought immediately and in full constant volume (as during static load), and the process dynamics is calculated by the respective levels of the applied load, with addition of the necessary complements to its static value.

Today, there are various methods allowing determination of track external load design values. The purpose of this work is to analyse these methods, to study the results of experimental testing of modern rolling stock action on track and to provide recommendations for their use.

\section{Methods for determining the design force acting on the rail}

\subsection{Probabilistic approach using statistical population of dynamic complements}

A probabilistic approach using statistical population of dynamic complements is the base one to determine the wheel design force acting on the rail in order to perform the so-called "Track strength and stability calculations". This calculation is the official method in Ukraine [1] and some other countries. It is used to solve such problems as determination of stresses and strains in the railway track elements caused by the rolling stock impact, determination of the required strength of permanent way for the set operation conditions, determination of operation conditions for the set track design (including allowable speeds in terms of strength and temperature mode of continuous welded rail operation), etc.

The calculation basis is the hypothesis that the wheel force acting on the rail has probabilistic nature and is subject to the law of Gaussian distribution. The example of the respective distribution curve is presented in the work [2], is shown in Fig. 1. The result is referred to the rail stress values observed for the same wheel load at the same speed.

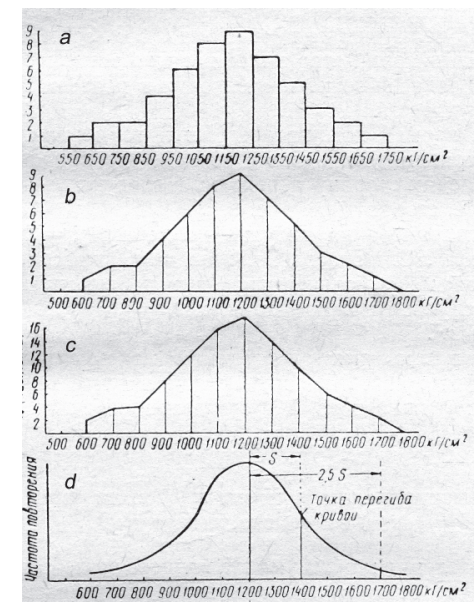

Figure 1. Probability of rail stress distribution [2]: $a$ - distribution histogram; $b-$ distribution polygon; $c$-frequency polygon; $d$-Gaussian distribution curve 
Most often there is a mean wheel force acting on the rail, but there can be both larger and smaller values. It is assumed that the design force is determined by the formula $[1 \ldots 3]$ :

$$
Q_{\mathrm{dyn}}=\bar{Q}+\lambda S,
$$

where

$Q_{\text {dyn }}:$ calculated (dynamic) value of force;

$\bar{Q}:$ mean value of force;

$\lambda$ : probability factor, is taken $\lambda=2.5$, corresponding to the non-exceedance probability of design force 0.994 ;

$S$ : root-mean-square deviation of force.

Mean value of dynamic force is made up of static load (vehicle weight referred to one wheel $\left(Q_{\text {stat }}\right)$ and the sum of mean values of dynamic complements $\left(\bar{Q}_{i}\right)$ :

$$
\bar{Q}=Q_{\text {stat }}+\sum \bar{Q}_{i}
$$

Total root mean square deviation consists of the geometric sum of the root-meansquare deviations of dynamic complements $\left(S_{i}\right)$ :

$$
S=\sqrt{\sum S_{i}^{2}} .
$$

Thus, each dynamic component is presented as the composition of its mean and rootmean-square deviation. As dynamic complements the following forces are taken into account: additional force due to vehicle bolster structure vibrations, inertial force due to wheel movement on the track bumps, inertial force of unsprung part from isolated irregularities on the wheel and inertial force of unsprung part from continuous irregularities on the wheel. The method of calculation of these dynamic complements is a set of analytical equations and approximations of experimental data. It is presented in the works $[1 \ldots 3]$ and others.

Thus, the considered approach makes it possible to determine the design force value taking into account the speed of movement and some key parameters associated with the design and the condition of railway track and rolling stock.

\subsection{Determination of dynamic force through static load}

The dynamic load of the track can be calculated from the static loads [4]:

$$
\begin{gathered}
Q_{\text {dyn }}=Q_{\text {stat }}+t \cdot \bar{s} \cdot Q_{\text {stat }}, \\
\bar{s}=n \cdot \varphi,
\end{gathered}
$$




$$
\varphi=1+\frac{V-60}{140}
$$

where

$t$ : distribution factor, if $t=3$ the accurary of calculation is $99.7 \%$;

$n: 0.1 \ldots 0.3$ (depends on the condition of trac);

$\varphi$ : speed factor (for speeds up to $60 \mathrm{~km} / \mathrm{h} \varphi=1[5]$ );

$V:$ speed in $\mathrm{km} / \mathrm{h}$.

The equation (6) may have a different look, for example, to take into account the type of the train (passenger or cargo) [5].

Examples of similar calculations: model for determination of the stress distribution in the longitudinal direction of the track [6]; the dynamic train loading was converted into an equivalent creep stress, using an equivalent static force method [7]; the investigation was aimed at static and dynamic load rating of aged railway concrete sleepers after service [8].

\subsection{Calculation of adjacent wheels action}

Wheels, located next to the calculated one, especially within the bogie, can affect the load level on the track. According to [1] such effect must be taken into account.

The basis is the known differential equation for rail deflection on equielastic support, used in many works, for example [2, 3, 9]:

$$
\frac{d^{4} z}{d x^{4}}+\frac{U}{E I} z=0,
$$

where

$z$ : vertical rail deflection;

$x$ : distance on rail from the force application point;

$U$ : modulus of rail support elasticity in the vertical plane;

$E$ : modulus of rail steel elasticity;

$I$ : moment of rail inertia.

Solution of the equation (7) will be the rail lengthwise deflection function

$$
\begin{gathered}
z(x)=\frac{Q k}{2 U} e^{-k x}(\cos k x+\sin k x), \\
k=\sqrt[4]{\frac{U}{4 E I}},
\end{gathered}
$$


where

\section{$Q$ : load taken for calculation}

Reverse solving of the equation (7) allows finding the effect of the force at a distance " $x$ " on the track design section. The method of "Track strength and stability calculations" [1] recommends transition from the design force to the equivalent one. The action of such a force must be equivalent to the load caused by the combination of several wheels. Given that the stress dependence on the distance to the force application point for rails and rail support is different, one determines two equivalent forces. The first equivalent force $\left(Q_{\mathrm{ekv}}^{\mathrm{I}}\right)$ is used to determine the bending moment and the stress in the rail, the second one ( $\left.Q_{\mathrm{ekv}}^{\mathrm{II}}\right)$ - to determine the rail deflection and the stress in the rail support elements (in sleepers, ballast, roadbed):

$$
\begin{gathered}
Q_{\mathrm{ekv}}^{\mathrm{I}}=Q_{\mathrm{dyn}}+\sum \bar{Q} \mu_{i}, \\
Q_{\mathrm{ekv}}^{\mathrm{II}}=P_{\mathrm{dyn}}+\sum \bar{Q} \eta_{i}, \\
\mu_{i}=e^{-k x_{i}}\left(\cos k x_{i}-\sin k x_{i}\right), \\
\eta_{i}=e^{-k x_{i}}\left(\cos k x_{i}+\sin k x_{i}\right),
\end{gathered}
$$

The formulas (10) and (11) are presented in the form meeting the hypothesis that the calculated wheel (which coincides with the calculated track section) transmits the calculated (dynamic) value of the force, and all other wheels - the mean value. Example of the variant, when the calculated wheel is the middle wheel of a three-axle bogie, is shown in Fig. 2 [3].

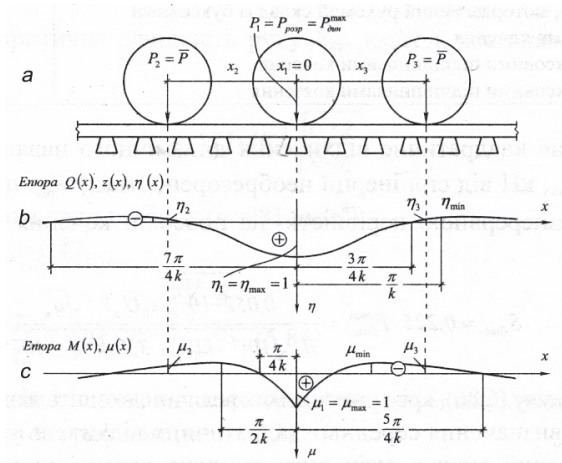

Figure 2. Load from three-axle bogie [4]: a-diagram of three-axle bogie; $b$-factor influence line $\eta(x) ; c$-factor influence line $\mu(x)$ 


\section{Experimental research of modern passenger train effect on the track}

The purpose of experimental research was practical assessment of dynamic effect on the track caused by the modern passenger trains to be operated in Ukraine with a fairly high speed. The experimental trials covered Talgo and Skoda trains. Talgo train consisted of KZ4A locomotive and articulated passenger cars adjacently rested on uniaxial bogies. Skoda train consisted of motor and towed cars separately rested on twoaxle bogies. The diagrams of the experimental trains are shown in Fig. 3 and 4.

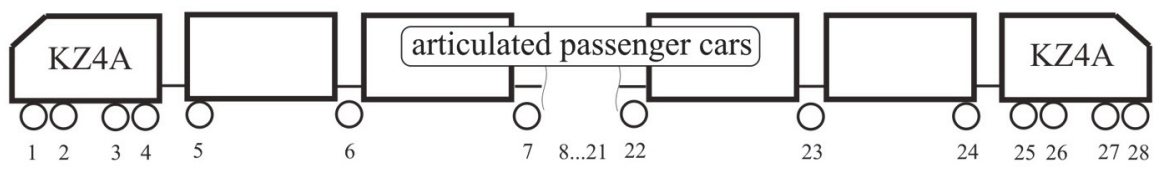

Figure 3. Diagram of experimental Talgo train

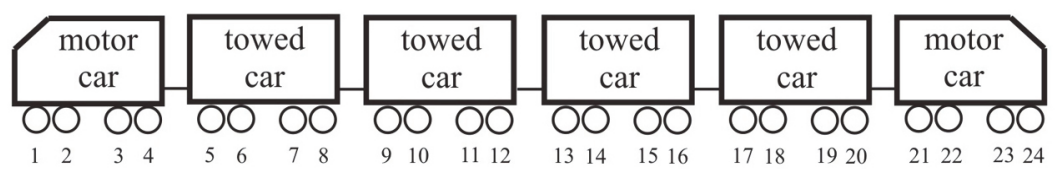

Figure 4. Diagram of experimental Skoda train

Experimental tests occurred on straight sections of the track without swerves requiring speed limit. The permanent way of both experimental sections was consisted of continuous welded rail R65, concrete sleepers, crushed stone ballast (including subballast) of min $60 \mathrm{~cm}$ below the sleepers. Maximum speed was 176 and $200 \mathrm{~km} / \mathrm{h}$ for Skoda and Talgo trains accordingly.

Organization and experiments were conducted by "Railway Track Testing Laboratory" of the Dnepropetrovsk National University of Railway Transport.

Some of the main indicators measured during the experimental train passing along the tested section were the rail stresses in several sections on top, web and base. Example of strain-gauge transducer installation in the rail section is shown in Fig. 5, example of stress record from the software window, which processed the data [10], - in Fig. 6.

The value of wheel vertical force acting on the rail was calculated based on the rail stress measurement results:

$$
Q=4 k W \sigma
$$

where

$W$ : rail moment resistance;

$\sigma$ : semi-sum of stresses, measured on the outside and the inside edge of the rail base. 


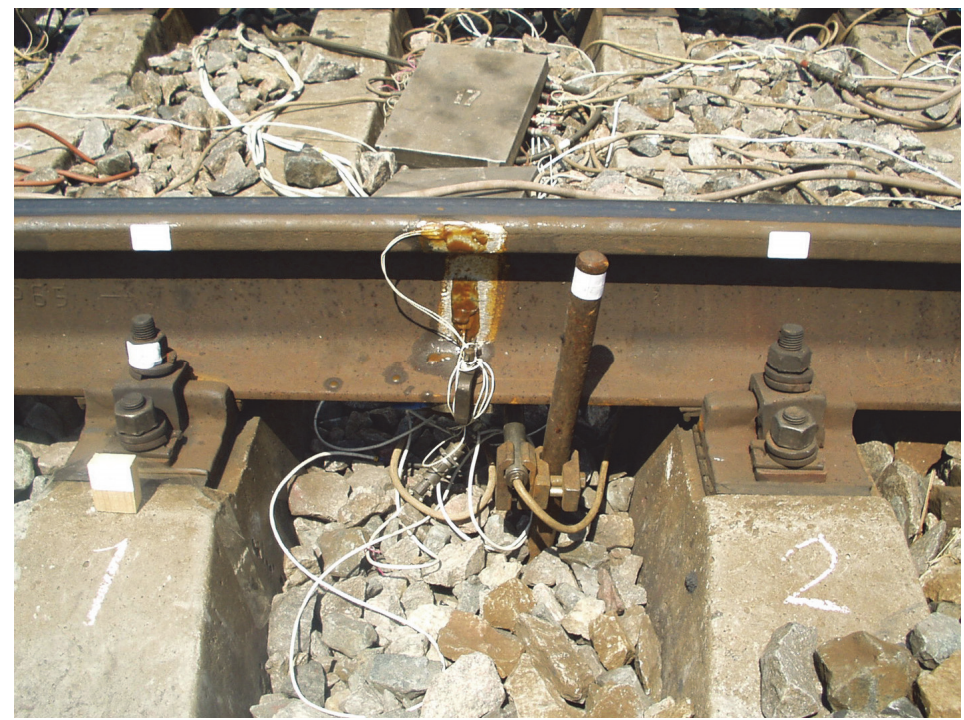

Figure 5. Installing transducers on a rail

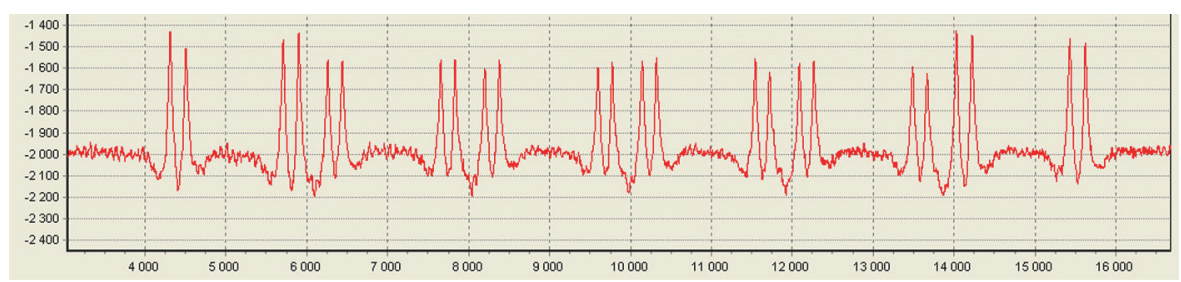

Figure 6. Example of rail stress record (stress on the base edge due to Skoda train passing at a speed of $176 \mathrm{~km} / \mathrm{h}$ )

The results of rolling stock unit weighing allowed receiving the static load level. Processing of statistic data showed sufficient compliance of resulting distribution of vertical force values with Gauss' law, Fig. 7. For each speed level we determined the mean value and the root-mean-square deviation of dynamic force. Some tasks of strain accumulation process modelling and other demand not only the most probabilistic value of the force, but also a range of its possible values. And to assess the wheel stability it is appropriate to conduct the calculations taking into account the probabilistic minimum value of vertical force. The design dynamic force was determined as the maximum (minimum) one with increase (decrease) probability of 0.994:

$$
Q_{\mathrm{dyn}}=\bar{Q} \pm 2.5 S \text {. }
$$




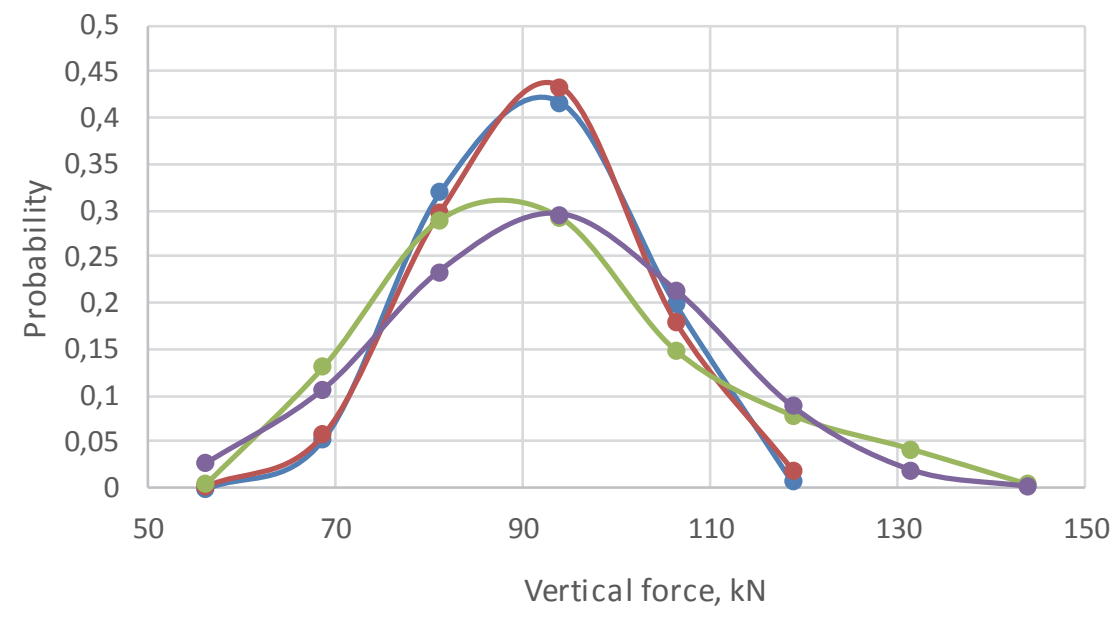

$\multimap$ resulting distribution $(80 \mathrm{~km} / \mathrm{h}) \multimap$ Gauss' law $(80 \mathrm{~km} / \mathrm{h})$

$\longrightarrow$ resulting distribution $(200 \mathrm{~km} / \mathrm{h}) \longrightarrow$ Gauss' law $(200 \mathrm{~km} / \mathrm{h})$

Figure 7. Law of distribution of the wheel vertical force on rail for Talgo train

The data processing results are shown in Fig. 8...11. For visual analysis, they are presented in the same horizontal and vertical scale.

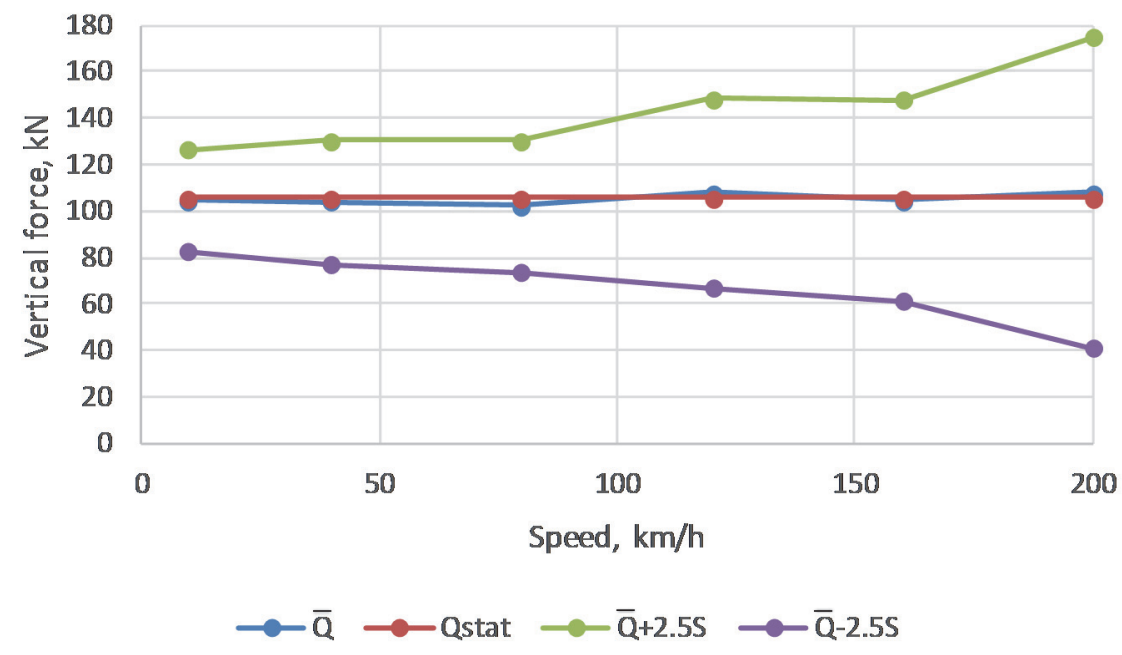

Figure 8. Vertical forces by experimental research on Talgo passenger train (for KZ4A locomotive) 


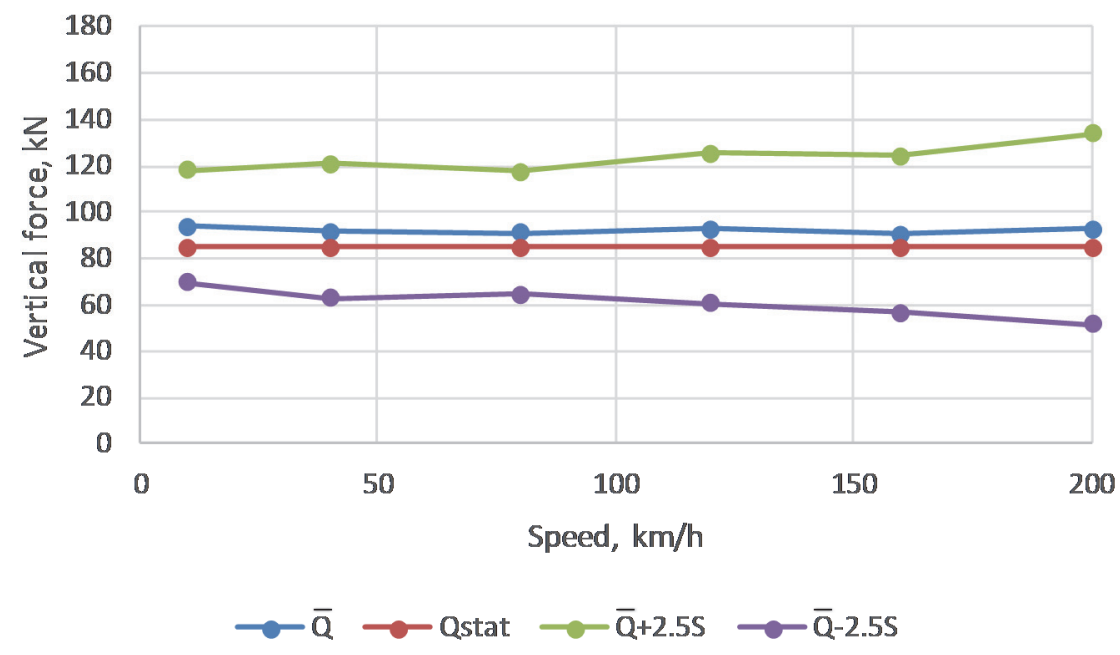

Figure 9. Vertical forces by experimental research on Talgo passenger train (for a car)
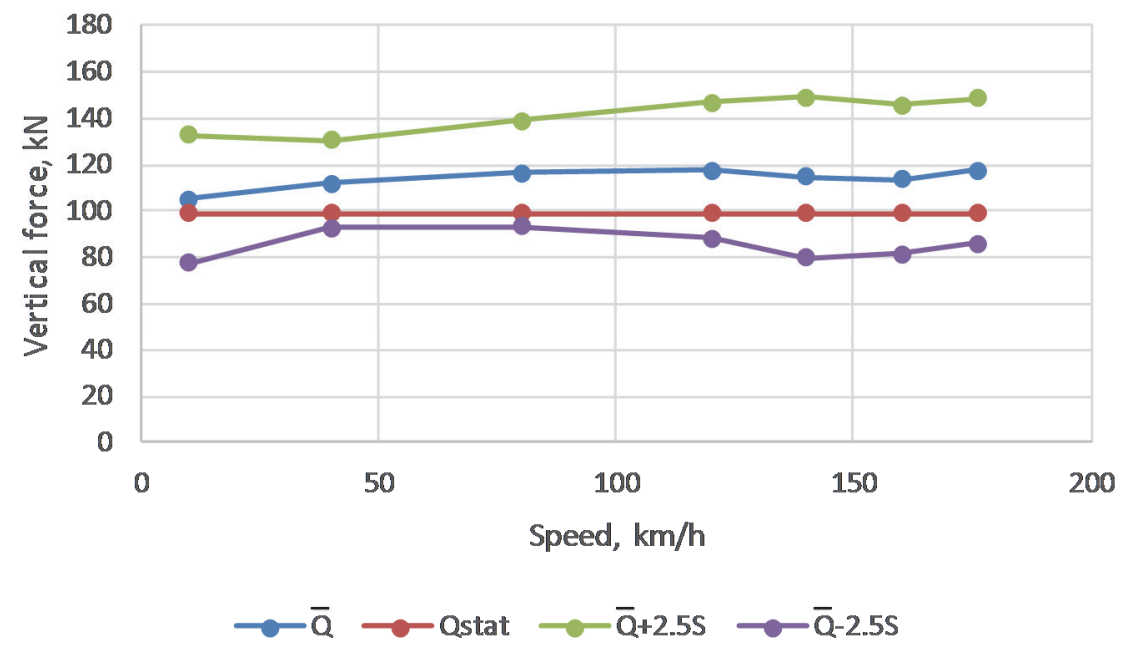

Figure 10. Vertical forces by experimental research on Skoda passenger train (for a motor car) 


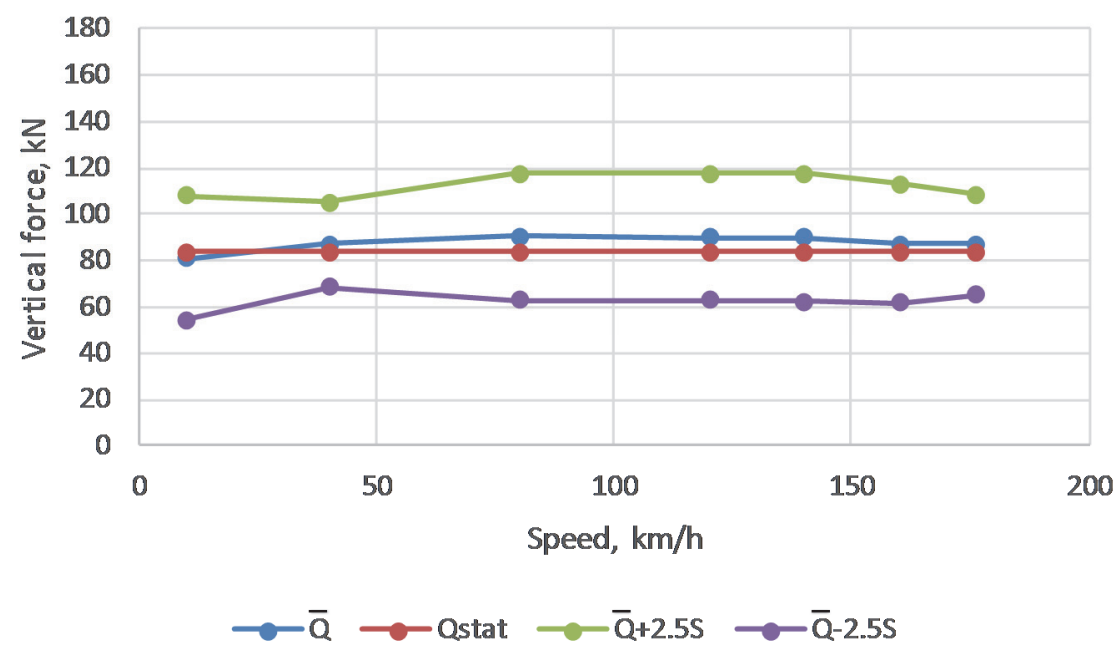

Figure 11. Vertical forces by experimental research on Skoda passenger train (for a motorless car)

\section{Analysis of factors affecting the value of dynamic force}

\subsection{Effect of bogie design and rail support elasticity}

In most cases the modern passenger and freight cars have two-axle bogies, and the locomotives have three or two-axle ones. Some methods of determining the rolling stock force acting on the track require taking into account of the bogie second (third) wheel effect, while the others ignore it.

The analysis of such effect was performed based on the formulas (10..13). The result depends mainly on two factors: distance from the calculated track section to the wheel and elastic modulus of the rail support. Particular attention was paid to the following groups of rolling stock: freight cars on CNII-H3-0 bogies with $185 \mathrm{~cm}$ axle base; locomotives with $210 \mathrm{~cm}$ axle base (such as 2TE10, M62 and others); passenger cars on KVZ-CNNI bogies with $240 \mathrm{~cm}$ axle base. As a rule, the locomotives with small axle base have three-axle bogies; in this case the track section under the middle axis is subject to the double additional load caused by outermost wheels.

The average values of the wheel effect on the track depending on the distance are shown in Fig. 12. As it can be seen, the pressure on the rail (correspondingly the rail section bending moment and the rail stress) away from the calculated section decreases rapidly and even enters the unloading area. Thus, when solving the rail stress tasks, the adjacent wheel effect can be neglected. However, the pressure on rail support (accordingly the rail deflection, the stress in sleeper, ballast, roadbed) may increase by more than $5 \%$ for freight cars and locomotives with a small rigid wheelbase (for the latter ones the results shown in Fig. 12 may be doubled for a three-axle bogie). For areas with low modulus of rail support elasticity the pressure increase on rail support may be significant, for example, up to $15 \%$ at $20 \mathrm{MPa}$ modulus of elasticity. 


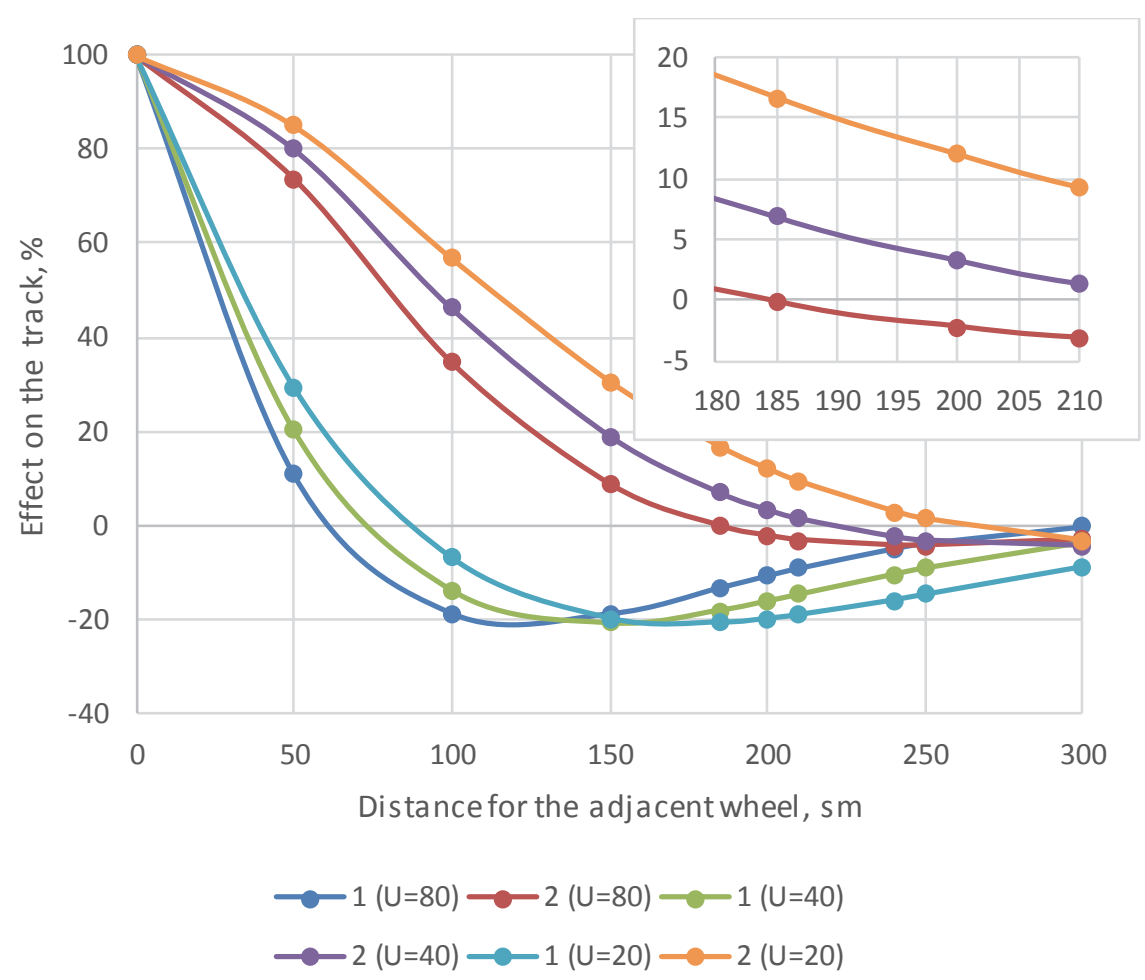

Figure 12. Wheel effect on the track depending on the distance for the modulus of rail support elasticity of 20, 40 and $80 \mathrm{MPa}: 1$ - pressure on the rail; 2-pressure on the rail support

The problem of operating the railway line built on soft soils with a small modulus of rail support elasticity is relevant for many European countries. Various scientific works investigated the dynamic effects that occur when driving on the track with such characteristics, especially in case of sufficient axial loading (freight trains) or high speeds (passenger trains) - [11...15]. Such operating conditions require the relevant rail support stabilization [16, 17], justified by experimental research and mathematical modelling [18] with the corresponding characteristics of railway track and the rolling stock loading.

\subsection{Effect of speed}

Modern passenger cars have significantly improved dynamic performance, primarily due to the transition from mechanical to hydraulic spring systems with automated control. This approach prevents from the dynamic load growth caused by speed increase. This conclusion is supported by experimental research conducted by the author. Thus, for the locomotive we observe almost linear dependence of maximum probabilistic force on the speed (Fig. 8) that corresponds to calculations according to the existing methods $[1,4]$. For motorless cars such force remains without significant 
changes even for high speeds (Fig. 9, 11). Similar conclusions for other types of rolling stock were obtained in the works [19, 20].

Even without expressed speed-dependence the vertical force dynamic component for passenger cars is evident. According to $[1,2,3]$ the main factors of the dynamic component are vehicle bolster structure vibrations and track vibrations due to its elastic properties and geometric irregularities.

Accordingly, to the experimental rail stress measurements for Talgo train was conducted factor variance analysis in order to obtain the numerical characteristics of various factors affecting the value of wheel vertical force acting on rail. Thus, the effect of the axle number was analysed (examined 8 axles of cars with approximately equal static load), which describes the effect of the structure and the condition of rolling stock. Also the work analysed the influence of rail section point (examined 8 sections with different distances on the area without sufficient swerves), which describes the effect of the wheel motion on track dynamic bumps that arise from rail vibrations. The total number of measurements in the observability matrix varied for different speed levels. The smallest number (for speed of $200 \mathrm{~km} / \mathrm{h}$ ) amounted to 560 values. For different speed values the assessment results of the considered factors effect do not change fundamentally. For the range of $40 \ldots 200 \mathrm{~km} / \mathrm{h}$ we obtained the effect degree (by F-test) of the car axle number at 1.7; the effect degree of the rail section number -120.0 while the level of F-test critical value for considered samples equals 2.02.

The performed statistical analysis confirms numerically that the body vibrations in modern passenger cars are efficiently damped and do not lead to a significant increase in wheel vertical pressure force on rail. The main dynamic force perturbation factor can be considered as the wheel passing over the dynamic track bumps, which appears even in the absence of significant geometrical irregularities due to the rail vibrations on elastic rail support.

\section{Summary}

The determination of dynamic force for stress and strain calculations in the rail support elements caused by freight cars or locomotives with the axle base of less than $230 \mathrm{~cm}$, especially for the track with modulus of rail support elasticity of up to $50 \mathrm{MPa}$, should take into account the additional pressure caused by the adjacent wheels. In other cases, the effect of the adjacent wheel is not essential. For modern passenger trains the level of the vertical force dynamic value does not depend on speed. The main factor for its determination should be the track vibrations as a result of its elastic properties and the presence of irregularities.

\section{Acknowledgement}

The author expresses gratitude to employees of "Railway Track Testing Laboratory" of the Dnepropetrovsk National University of Railway Transport, especially to Evgeniy Savluk and Olena Toropina for organizing and conducting the experiments. 


\section{References}

[1] Danilenko EI, Rybkin VV: The computations rules of the railway track for strength and stability. TsP- 0117. Kyiv, Transport Ukrainy Publ., 64 p, 2004

[2] Chernyshov MA: Practical method of the track computation. Moscow, Transport Publ., 236 p, 1967

[3] Danilenko EI: Railway track. Structure, planning and calculations, interaction with rolling stock. Kyiv, Inpres Publ., Vol. 2. 456 p, 2010

[4] Fisher S, Eller B, Kada Z, Attila N: Railway construction Railway construction. Györ, 334 p, 2015

[5] Lichtberger B: Thack compendium. Eurailpress Tetzlaff-Hestra GmbH \& Co. KG, Hamburg, 634 p, 2005

[6] Suiker AS, de Borst R: A numerical model for the cyclic deterioration of railway tracks. International journal for numerical methods in engineering, Vol. 57, pp. 441-470, 2003 DOI: $10.1002 / \mathrm{nme} .683$

[7] Ma W, Chen T: Analysis of permanent deformations of railway embankments under repeated vehicle loadings in permafrost regions. Sciences in Cold and Arid Regions, Vol. 7, No. 6, pp. 645-653, 2015

DOI: $10.3724 /$ SP.J.1226.2015.00645

[8] Remennikov AM, Kaewunruen S: Experimental load rating of aged railway concrete sleepers. Engineering Structures, Vol. 76, pp. 147-162, 2014 DOI: 10.1016/j.engstruct.2014.06.032

[9] Major Z: Longitudinal Behaviour of Embedded Rails. Acta Technica Jaurinensis, Vol. 8, No. 2, pp. 179-187, 2015

DOI: 10.14513/actatechjaur.v8.n2.367

[10] Bondarenko IO, Kurgan DM, Patlasov OM, Savluk VYe: Using of digital instrumentation equipment for experimental researches of track and rolling stock interaction. Science and Transport Progress. Bulletin of Dnipropetrovsk National University of Railway Transport, No. 37, pp. 124-128, 2011

[11] Connolly D, Giannopoulos A, Forde M: Numerical modelling of ground borne vibrations from high speed rail lines on embankments. Soil Dynamics and Earthquake Engineering, Vol. 46, pp. 13-19, 2013

DOI: 10.1016/j.soildyn.2012.12.003

[12] Krylov VV, Dawson AR, Heelis ME, Collop AC: Rail movement and ground waves caused by high-speed trains approaching track-soil critical velocities. Proc. of The Institution of Mechanical Engineers Part F-journal of Rail and Rapid Transit - PROC INST MECH ENG F-J RAIL R, Vol. 214, No. 2, pp. 107-116, 2000

DOI: $10.1243 / 0954409001531379$

[13] Kouroussis G, Van Parys L, Conti C, Verlinden O: Using three-dimensional finite element analysis in time domain to model railway-induced ground vibrations.

Advances in Engineering Software, Vol. 70, pp. 63-76, 2014

DOI: $10.1016 /$ j.advengsoft.2014.01.005

[14] Woldringh RF, New BM: Embankment design for high speed trains on soft soils. Proc. of the 12th Europ. Conf. on Soil Mechanics and Geotechnical Engineering (7.06-10.06.1999), Amsterdam, The Netherlands, Vol. 3, pp. 1703-1712, 1999 
[15] Kurhan DM: Features of perception of loading elements of the railway track at high speeds of the movement. Science and Transport Progress. Bulletin of Dnipropetrovsk National University of Railway Transport, No. 56, pp. 136-145, 2015

DOI: $10.15802 /$ stp2015/42172

[16] Koch E, Szepesházi R: Mélykeveréses technológia vasútépítési alkalmazásának lehetőségei. Sínek Világa, Vol. 2, pp. 9-14, 2013

[17] Petrenko V, Sviatko I: Simulation of subgrade embankment on weak base. Science and Transport Progress. Bulletin of Dnipropetrovsk National University of Railway Transport, No. 58, pp. 198-204, 2015

DOI: $10.15802 /$ stp2015/49286

[18] Fischer S: Investigation of inner shear resistance of geogrids built under granular protection layers and railway ballast. Science and Transport Progress. Bulletin of Dnipropetrovsk National University of Railway Transport, No. 59, pp. 97-106, 2015

DOI: $10.15802 / \mathrm{stp} 2015 / 53169$

[19] Holder DE, Williams BA, Dersch MS, Edwards JR, Barkan CP: Quantification of Lateral Forces in Concrete Sleeper Fastening Systems Under Heavy Haul Freight Loads. Perth, Australia, 2015

[20] Manda KR, Dersch M, Kernes R, Edwards RJ, Lange DA: Vertical load path under static and dynamic loads in concrete crosstie and fastening systems. In 2014 Joint Rail Conference, pp. V001T01A025-V001T01A025, 2014 DOI: $10.1115 / J R C 2014-3832$ 